\title{
ANALISIS REGRESI BERGANDA DENGAN METODE STEPWISE PADA DATA HBAT
}

\author{
FERRY KONDO LEMBANG \\ Staf Jurusan Matematika, FMIPA, Unpatti \\ J1. Ir. M. Putuhena, Kampus Unpatti, Poka-Ambon \\ e-mail: free_maxpluz16@yahoo.com
}

\begin{abstract}
Multiple regression analysis as a statistical technique that can be used to analyze the relationship between a single dependent (respon) variable and several independent (peredictor) variables. Application for this analysis to be done specially in social economic. HBAT is a manufacture of paper products. Surveys of HBAT customer will be used to application multiple regression analysis in this paper to explain relationship satisfication between the other variables. Methods to selective entering and deleting among these variables until some overall criterion measure is achived. Objective methods for selecting variables that maximizes the prediction while employing the smallest number of variables. Results is the best model from multiple regression analysis is $\mathrm{Y}=-1.15106+0.36900 \mathrm{X} 6$ 0.41714 X7 +0.31896 X9 $+0.17435 X 11+0.77513$ X12, means that customer satisfaction is significantly influenced by the complaint resolution, product quality, salesforce image, ecommerce activities, and product line. Besides that the assumptions in multiple regression analysis are met. SAS software has facility more complete than SPSS, Minitab, and R.
\end{abstract}

Keywords: multiple regression analysis HBAT, stepwise, Corellation, SAS, SPSS, Minitab, $R$

\section{PENDAHULUAN}

HBAT merupakan perusahaan yag bergerak di bidang industri khususnya untuk produksi produk kertas. Data HBAT dipakai sebagai data sekunder dalam menjelaskan dan mengilustrasikan beberapa teknik analisis multivariat. Semua data yang ada dalam data HBAT merupakan data hasil survey terhadap pelanggan HBAT yang kemudian dikelola oleh sebuah perusahaan riset unggulan. Beberapa teknik analisis multivariat yang menggunakan data HBAT antara lain, Analisis Faktor, Analisis Diskriminan, dan juga beberapa metode Analisis Regresi. Khusus untuk metode Analisis Regresi biasanya untuk model persamaan regresi linear berganda, umumnya penelitian difokuskan mengenai pemilihan model regresi terbaik, dimana prosedur ini memungkinkan penentuan peubah atau variabel yang akan dimasukkan ke dalam regresi. Adapun tujuan pemilihan model regresi terbaik biasanya untuk kepentingan peramalan dan mencegah pengeluaran biaya yang tinggi dalam memperoleh informasi dari peubah atau variabel mengingat aplikasi analisis regresi telah banyak dipakai dalam dunia bisnis dan marketing.
Pemilihan model regresi terbaik dalam ilmu statistika yang umumnya sering digunakan, antara lain metode regresi Backward, metode Regresi Forward, dan Metode Regresi Stepwise.

Penelitian regresi linier berganda untuk kepentingan peramalan telah banyak dilakukan antara lain, Supriyono (2007) membandingkan logika fuzzy dengan regresi berganda sebagai alat peramalan, Pujiati (2005) melakukan analisis regresi berganda untuk mengetahui hubungan antara beberapa aktifitas promosi dengan penjualan produk. Berdasarkan penelitian yang telah dilakukan oleh Pujiati, agar model yang diperoleh dapat mudah diinterpretasikan, sebaiknya pada saat analisa/ interpretasinya dikembalikan pada nilai sebenarnya. Namun kelemahan dari penelitian ini adalah belum disimpulkan apakah model regresi yang didapat adalah model terbaik untuk kasus diatas.

Tertarik dengan penelitian Pujiati, maka untuk menjawab kelemahannya dalam penulisan ini akan digunakan metode pemilihan model regresi terbaik yaitu, metode Stepwise. Adapun pemilihan metode Stepwise karena dapat menyelesaikan masalah regresi yang variabel prediktornya saling berkorelasi. Selain itu, 
pemecahannya akan dianalisis dengan empat software antara lain SPSS, Minitab, R, dan SAS. Tujuan dari penulisan ini adalah mendapatkan model regresi terbaik dari data HBAT dengan prosedur Stepwise. Penelitian ini diharapkan dapat digunakan sebagai informasi analisa data bagi perusahaan yang bergerak di bidang bisnis dan marketing untuk meningkatkan usaha dan bagi pemerhati statistik dalam memperdalam konsep analisis regresi linier berganda khususnya untuk pemilihan model regresi terbaik.

\section{TINJAUAN PUSTAKA}

Analisis Regresi Linier Berganda adalah suatu metode statistik umum yang digunakan untuk meneliti hubungan antara satu variabel dependen (Y) dengan beberapa variabel independen $\left(\mathrm{X}_{1}, \mathrm{X}_{2}, \ldots, \mathrm{X}_{\mathrm{K}}\right)$ (Drapper and Smith, 1992; Hair, Black, Babin, Anderson,\&Tatham, 2006, P.176; Cohen, Cohen, West, and Aiken, 2003; Johnson, R.A. and Wichern, D.W, 2002). Tujuan analisis regresi berganda adalah menggunakan nilai-nilai variabel dependen yang diketahui, untuk meramalkan nilai variabel dependen. Persamaan umum dari regresi linier beganda adalah

$$
\mathrm{Y}=\beta_{0}+\beta_{1} \mathrm{X}_{1}+\beta_{2} \mathrm{X}_{2}+\mathrm{L}+\beta_{\mathrm{k}} \mathrm{X}_{\mathrm{k}}+\varepsilon
$$

dengan $\mathrm{Y}=$ variabel dependen yang diprediksi

$$
\begin{aligned}
& \beta_{0}, \beta_{1}, \beta_{2}, \ldots, \beta_{\mathrm{k}}=\text { parameter } \\
& \mathrm{X}_{1}, \mathrm{X}_{2}, \mathrm{~L}, \mathrm{X}_{\mathrm{k}}=\text { variabel independen }
\end{aligned}
$$

Jika terdapat variabel dependen $\mathrm{Y}$ yang dipenuhi oleh sekumpulan variabel $\mathrm{X}$, maka agar bermanfaat ingin dimasukkan sebanyak mungkin variabel $X$ sehingga didapatkan keterhandalan yang tinggi, tetapi untuk kepentingan monitoring seringkali lebih diharapkan jumlah X yang kecil, sehingga komprominya adalah dipilih persamaan regresi terbaik. Adapun prinsip persamaan regresi terbaik adalah

- semua variabel independen yang masuk signifikan

- menghasilkan koefisien determinasi yang tinggi

- MS residualnya kecil

- Memakai konsep parsimony

Metode pencarian secara berurutan (sequential search) merupakan suatu metode untuk mengestimasi persamaan regresi dengan mempertimbangkan variabelvariabel yang sudah didefinisikan oleh peneliti dan secara selektif menambah dan mengurangi diantara variabelvariabel tersebut sampai semua kriteria terpenuhi. Ada dua pendekatan dalam metode ini yaitu estimasi stepwise dan penambahan forward dan eliminasi backward. Metode estimasi stepwise dilakukan dengan memasukkan variabel independen yang mempunyai konstribusi terbesar terhadap variabel dependen, hal ini dilakukan secara terus menerus sampai semua varibel independen yang mempunyai konstribusi signifikan (Brown, 1993; Kokaly and Clark, 1999; Nielsen, Stapelfeldt, and Skibsted, 1997; Sun, Zhao, and Yan, 1995; Wilkinson, 1979). Tujuan dilakukan metode ini untuk mencari model regresi terbaik.

\section{METODOLOGI PENELITIAN}

Data yang digunakan pada penelitian ini adalah data sekunder mengenai hasil survey konsumen HBAT yaitu perusahaan penghasil kertas (Hair dkk, 2006). Banyaknya konsumen atau perusahaan yang disurvey dalam data ini adalah 100 perusahaan dengan variabel sebanyak 18 . Penelitian ini hanya menggunakan 13 variabel prediktor dan satu variabel respon. Adapun variabel yang digunakan adalah

Variabel respon

$\mathrm{Y}=$ kepuasan pelanggan

Variabel prediktor

$\mathrm{X} 6=$ Kualitas produk

$\mathrm{X} 7$ = Aktivitas E-commerce

$\mathrm{X} 8$ = penunjang tehnik (technical support)

$\mathrm{X} 9$ = Tanggapan terhadap complain

$\mathrm{X} 10=$ periklanan

$\mathrm{X} 11=$ product line

$\mathrm{X} 12$ = image dari sales

$\mathrm{X} 13$ = kompetisi harga

$\mathrm{X} 14$ = Garansi dan klaim

$\mathrm{X} 15=$ produk baru

$\mathrm{X} 16$ = pemesanan dan pembayaran

$\mathrm{X} 17=$ harga yang fleksibel

X18 = kecepatan pengiriman

Analisis yang akan dilakukan pada data penelitian tersebut adalah regresi linear berganda dengan tujuan untuk mengetahui model terbaik antara satu variabel respon dan 13 variabel prediktor dengan menggunakan metode stepwise. Analisis dilakukan dengan menggunakan 4 software yaitu SPSS (Ho, 2006, PP 195 201), MINITAB, SAS (Khattre and Naik, 1999; Schlotzhauer and Littell 1997) dan R (Braun and Murdoch, 2007).

\section{HASIL DAN PEMBAHASAN}

Analisis data dilakukan dengan menggunakan enam langkah dalam membangun model pada analisis multivariat (Hair dkk, 2006). Langkah awal sebelum melakukan regresi linear berganda terlebih dahulu dilakukan pengujian untuk mengetahui layak atau tidaknya suatu penelitian dianalisis dengan menggunakan analisis ini. Pengujian awal yang digunakan adalah melihat apakah ada korelasi antara variabel respon dan setiap variabel prediktor. Scatter plot antara variabel respon dan variabel prediktor merupakan salah satu alat yang dapat digunakan untuk melihat apakah ada korelasi yang signifikan antara variabel-variabel dalam plot. Secara visual plot antara variabel respon dengan masingmasing variabel prediktor dapat dilihat pada Gambar 1.

Ada hubungan antara variabel respon dengan masing-masing variabel prediktor, akan tetapi ada beberapa variabel prediktor yang terlihat tidak berkorelasi dengan variabel respon diantaranya X8, X14, X15 dan $\mathrm{X} 17$, hal ini dapat dilihat dari bentuk scatter plot yang tidak menunjukkan trend naik atau turun, akan tetapi menyebar secara random. Berdasarkan pengujian ini maka analisis data pada penelitian ini dapat menggunakan analisis regresi berganda. Disamping itu, korelasi antar 
variabel prediktor menunjukkan bahwa ada multikolinearitas sehingga pada analisis selanjutnya akan di seleksi variabel-variabel prediktor yang secara signifikan memberikan konstribusi terhadap variabel responden.

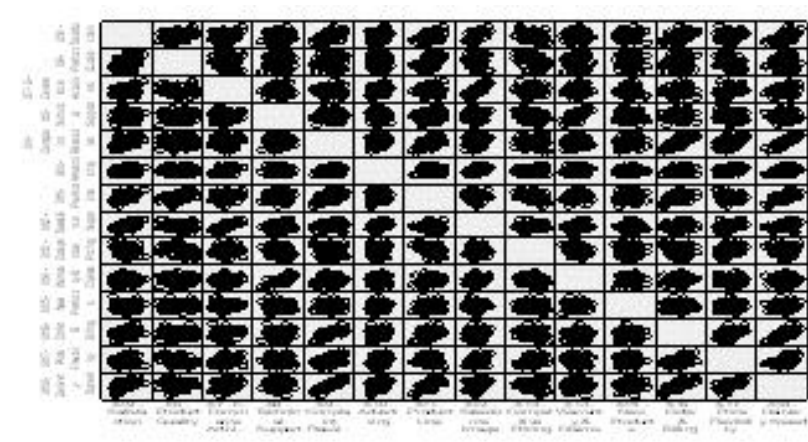

Gambar 1 Scatter plot antara variabel respon dan setiap variabel prediktor

Langkah selanjutnya memodelkan antara variabel respon $(\mathrm{X} 19)$ dan variabel prediktor $(\mathrm{X} 6, \mathrm{X} 7, \mathrm{X} 8, \mathrm{X} 9$, $\mathrm{X} 10, \mathrm{X} 11, \mathrm{X} 12, \mathrm{X} 13, \mathrm{X} 14, \mathrm{X} 15, \mathrm{X} 16, \mathrm{X} 17$, dan X18) dengan menggunakan metode stepwise. Metode ini dilakukan dengan seleksi jika $\alpha \leq 0,05$ maka variabel prediktor masuk dalam model dan variabel akan dikeluarkan dari model jika $\alpha \leq 0,1$. Nilai $\alpha$ adalah nilai probailitas dari pengujian korelasi parsial antara variabel respon dengan masing-masing dari variabel prediktor. Adapun hasil analisis dengan menggunakan metode stepwise dapat dirinci dalam beberapa tahap berikut :

Tabel 1. Hasil dari tahap 1

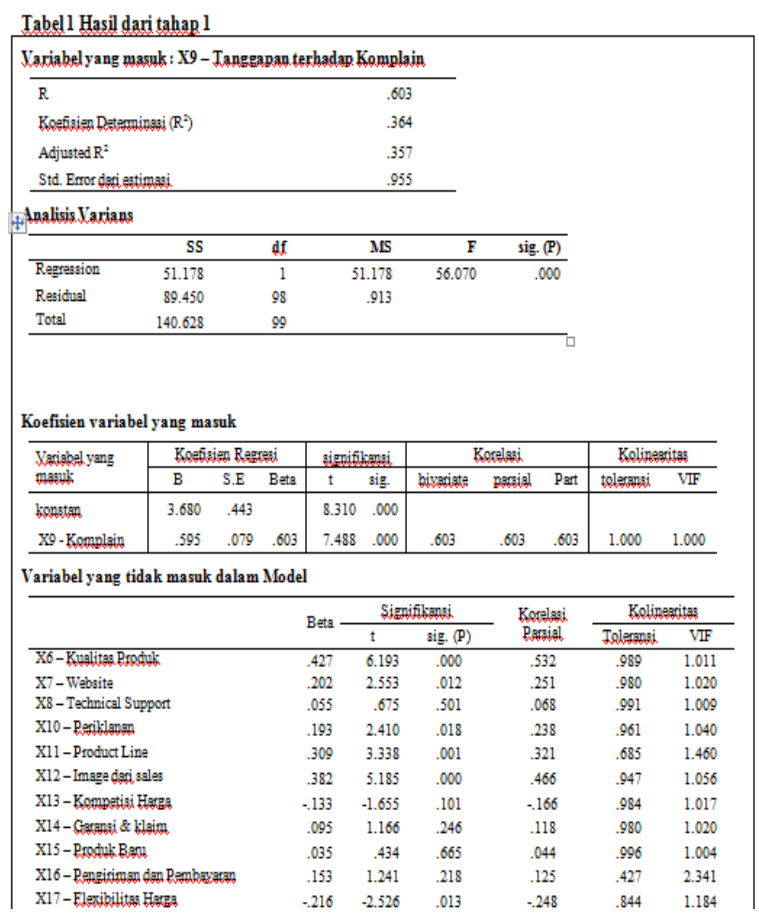

Tahap 1: Melihat nilai korelasi terbesar antara variabel respon dengan masing-masing variabel prediktor dalam model, didapatkan nilai korelasi terbesar antara X19 dengan X9 yaitu 0,603 sehingga X9 dimasukkan dalam model. Selanjutnya, memodelkan X19 dengan X9 untuk mengetahui apakah X9 layak masuk dalam model dengan melakukan pengujian-pengujian yang diperlukan. Berdasarkan output komputer maka X9 layak masuk dalam model karena koefisien regresi $(\beta)$ signifikan pada $\alpha=0,05$ dengan pengujian secara individu dan serentak. Hasil lebih lengkap dapat dilihat pada Tabel

Tahap 2 : Melihat nilai korelasi parsial antara model pada tahap 1 dengan masing-masing variabel prediktor yang lain, didapatkan nilai korelasi parsial terbesar dengan X6 yaitu 0,532 sehingga X6 dimasukkan dalam model. Selanjutnya, memodelkan X19 dengan X9 dan X6 untuk mengetahui apakah X9 dan X6 layak masuk dalam model dengan melakukan pengujian-pengujian yang diperlukan. Berdasarkan output komputer maka X9 dan X6 layak masuk dalam model karena koefisien regresi $(\beta)$ signifikan pada $\alpha=0,05$ dengan pengujian secara individu dan serentak serta nilai $\mathrm{R}^{2}$ dari model sebesar 0,544 . Secara leih lengkap dapat dilihat pada Tabel 2

Tabel 2. Hasil dari Tahap 2

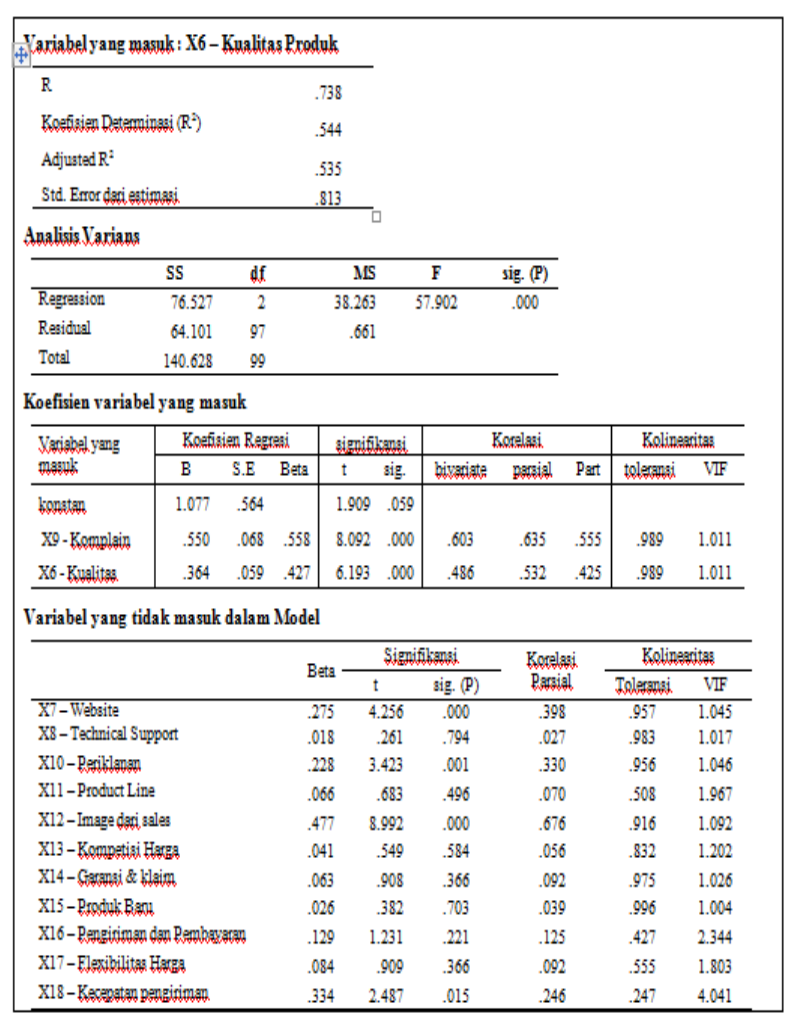

Tahap 3 : Melihat nilai korelasi parsial antara model pada tahap 2 dengan masing-masing variabel prediktor yang lain, didapatkan nilai korelasi parsial terbesar dengan X12 yaitu 0,676 sehingga X12 dimasukkan dalam model. Selanjutnya, memodelkan X19 dengan X9, X6 dan X12 untuk mengetahui apakah X9, X6 dan X12 layak masuk dalam model dengan melakukan pengujian-pengujian yang diperlukan. Berdasarkan output komputer maka X9, X6 dan X12 layak masuk dalam model karena koefisien regresi $(\beta)$ signifikan pada $\alpha=0,05$ dengan pengujian secara individu dan serentak serta nilai $\mathrm{R}^{2}$ dari model sebesar 0,753. Tabel 3 merupakan hasil lengkap tahap 3 
Tabel 3. Hasil dari Tahap 3

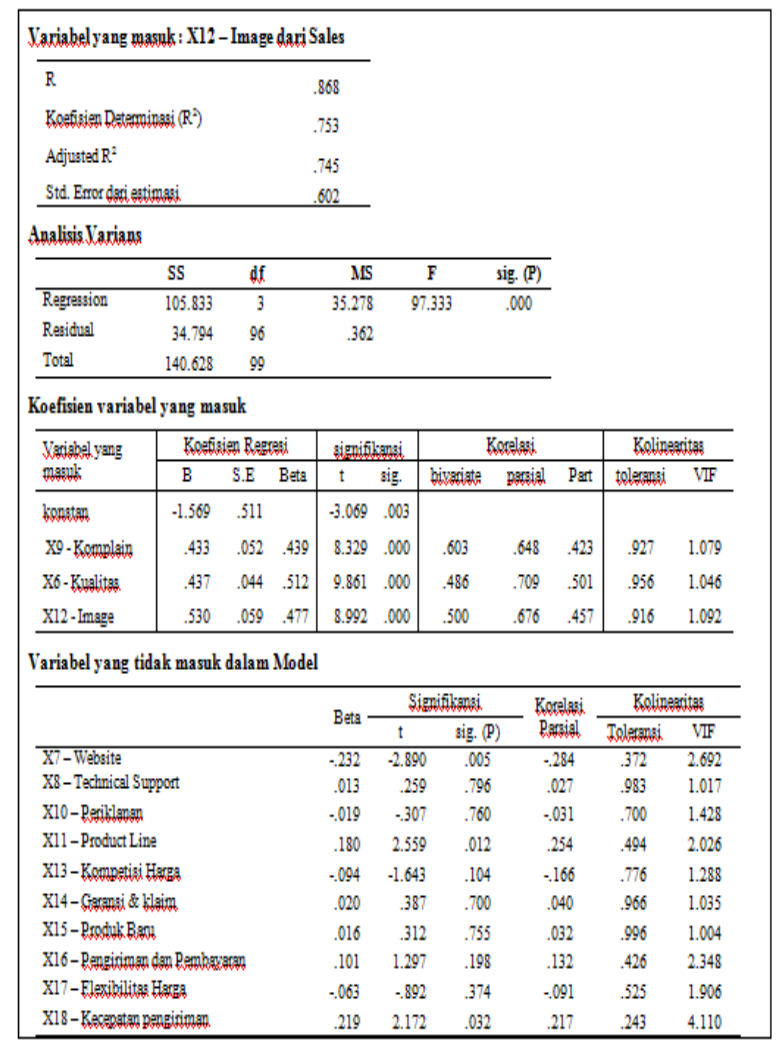

Tabel 4. Hasil dari Tahap 4

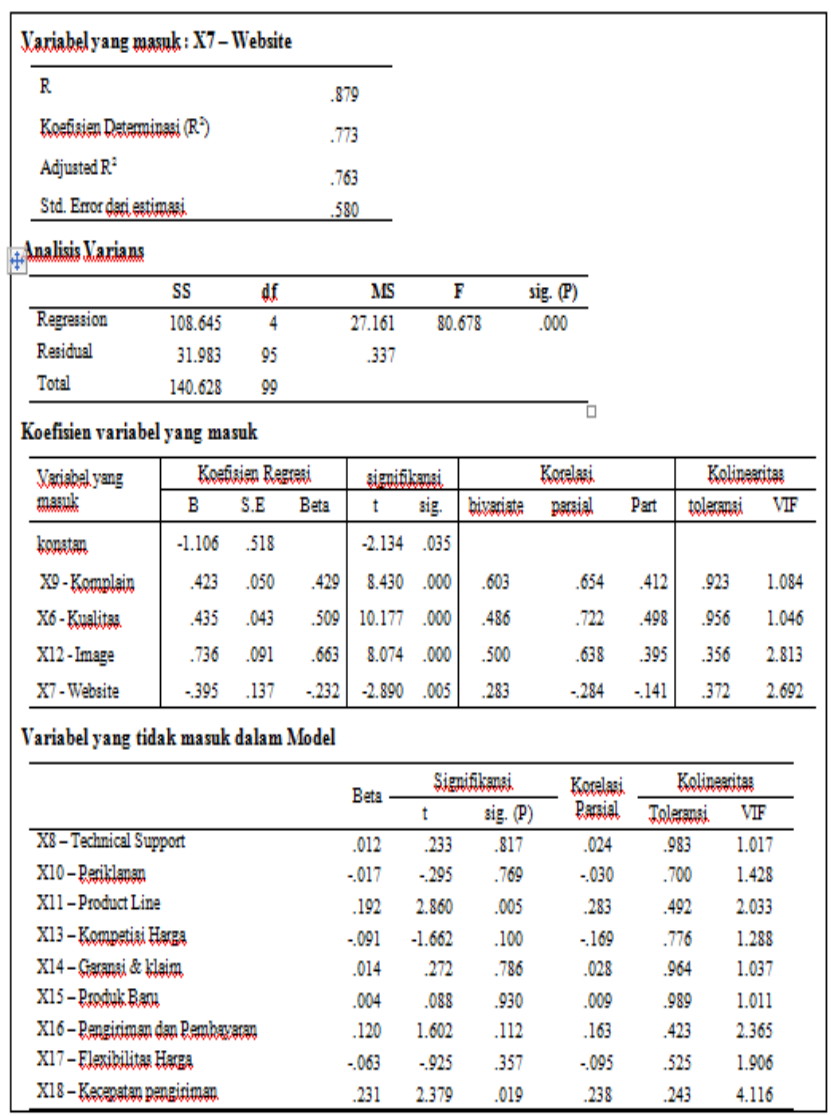

Tahap 4 : Melihat nilai korelasi parsial antara model pada tahap 3 dengan masing-masing variabel prediktor yang lain, didapatkan nilai korelasi parsial terbesar dengan $\mathrm{X} 7$ yaitu -0,284 sehingga X7 dimasukkan dalam model. Selanjutnya, memodelkan X19 dengan X9, X6, X12 dan X7 untuk mengetahui apakah X9, X6, X12, dan X7 layak masuk dalam model dengan melakukan pengujianpengujian yang diperlukan. Berdasarkan output komputer maka X9, X6, X12 dan X7 layak masuk dalam model karena koefisien regresi $(\beta)$ signifikan pada $\alpha=0,05$ dengan pengujian secara individu dan serentak serta nilai $\mathrm{R}^{2}$ dari model sebesar 0,773 . Selengkapnya pada Tabel 4 .

Tahap 5 : Melihat nilai korelasi parsial antara model pada tahap 4 dengan masing-masing variabel prediktor yang lain, didapatkan nilai korelasi parsial terbesar dengan X11 yaitu -0,284 sehingga X11 dimasukkan dalam model. Selanjutnya, memodelkan X19 dengan X9, X6, X12, X7 dan X11 untuk mengetahui apakah X9, X6, X12, X7 dan X11 layak masuk dalam model dengan melakukan pengujian-pengujian yang diperlukan. Berdasarkan output komputer maka X9, X6, X12, X7 dan X11 layak masuk dalam model karena koefisien regresi $(\beta)$ signifikan pada $\alpha=0,05$ dengan pengujian secara individu dan serentak serta nilai $\mathrm{R}^{2}$ dari model sebesar 0,791. Hasil lengkap pada Tabel 5.

Tabel 5. Hasil dari Tahap 5

\begin{tabular}{|c|c|c|c|c|c|c|c|c|c|c|}
\hline \multicolumn{5}{|c|}{ Variabel yang masuls: Xl1 - Product Line } & & & & & & \\
\hline \multicolumn{2}{|l|}{$\mathrm{R}$} & \multicolumn{3}{|c|}{.889} & & & & & & \\
\hline \multicolumn{2}{|c|}{ Koefisien Detemingasi ( $\left(R^{2}\right)$} & \multicolumn{3}{|c|}{.791} & & & & & & \\
\hline \multicolumn{2}{|c|}{ Adjusted $R^{2}$} & \multicolumn{3}{|c|}{.780} & & & & & & \\
\hline \multicolumn{2}{|c|}{ Std. Exror dari attimasi } & \multicolumn{3}{|c|}{.559} & & & & & & \\
\hline \multicolumn{11}{|l|}{ Analisis Varians } \\
\hline & SS & \multicolumn{2}{|c|}{ df } & MS & \multicolumn{2}{|c|}{$\mathrm{F}$} & sig. (P) & & & \\
\hline Regrastion & 111.205 & \multicolumn{2}{|c|}{5} & 22.241 & \multirow{2}{*}{\multicolumn{2}{|c|}{71.058}} & \multirow[t]{2}{*}{.000} & & & \\
\hline Residual & 29.422 & 94 & & .313 & & & & & & \\
\hline Total & 140.628 & 99 & & & & & & & & \\
\hline \multicolumn{11}{|c|}{ Koefisien variabel yang masuk } \\
\hline \multirow{2}{*}{$\begin{array}{l}\text { Variagel yang } \\
\text { masul }\end{array}$} & \multicolumn{3}{|c|}{ Kaefigisen Rereresi } & \multicolumn{2}{|c|}{ sigmifikansi } & \multicolumn{3}{|c|}{$\begin{array}{r}\text { Korelasi } \\
\end{array}$} & \multicolumn{2}{|c|}{ Kolinearitas } \\
\hline & $\mathrm{B}$ & S.E & Bets & $\mathrm{t}$ & sig. & bivariate & parsigl & Part & tolengsi & VIF \\
\hline kopetan & -1.151 & .500 & & -2.303 & .023 & & & & & \\
\hline $\mathrm{X} 9$ - Komplain & .319 & .061 & .323 & 5.256 & .000 & .003 & .477 & .248 & .588 & 1.701 \\
\hline X6-Kulitges & .369 & .047 & .432 & 7.820 & .000 & .486 & .628 & .369 & .728 & 1.373 \\
\hline X12-Image & .775 & .089 & .697 & 8.711 & .000 & .500 & .668 & .411 & .347 & 2.880 \\
\hline X7-Website & .417 & .132 & .245 & -3.162 & .002 & .283 & -310 & .149 & .370 & 2.701 \\
\hline Xl1-Line & .174 & .061 & .192 & 2.860 & .005 & .551 & .283 & .135 & .492 & 2.033 \\
\hline \multicolumn{11}{|c|}{ Wariabel yang tidak masuk dalam Model } \\
\hline & & & & \multirow{2}{*}{ Beta } & \multicolumn{2}{|c|}{ Sigmifilangi } & Korelagi & \multicolumn{3}{|c|}{ Kolinearitas } \\
\hline & & & & & $\mathrm{t}$ & sig. (P) & Parsial & Inleren: & $\mathrm{mag} . \mathrm{VI}$ & \\
\hline \multicolumn{4}{|c|}{ X8-Techrical Support } & -.009 & -.187 & .852 & -019 & 9.961 & 1.04 & \\
\hline \multicolumn{4}{|c|}{$\mathrm{X} 10-$ Rerillangen } & .009 & -162 & .872 & .017 & 7.698 & 1.43 & \\
\hline \multicolumn{4}{|c|}{ X13-Kempetisi Harga } & .040 & .685 & .495 & .071 & 1.667 & 1.49 & \\
\hline X14-Garansi \& & & & & .023 & -462 & .645 & .048 & 8.901 & 1.11 & \\
\hline $\mathrm{X} 15$ - Produlus B & & & & .002 & .050 & .960 & .005 & 5.989 & 1.01 & \\
\hline $\mathrm{X} 16$-Pengirims & In Pembar & & & .124 & 1.727 & .088 & .176 & 6.423 & 2.36 & \\
\hline X17-Elexibilite & & & & .12 & 1.429 & .156 & .147 & 7.272 & 3.67 & \\
\hline X18-Kescasten & ngiximann & & & .138 & 1.299 & 197 & .133 & $\begin{array}{l}3.197 \\
\end{array}$ & 5.07 & \\
\hline
\end{tabular}

Tahap 6 : Melihat nilai korelasi parsial antara model pada tahap 5 dengan masing-masing variabel prediktor yang lain, didapatkan nilai korelasi parsial terbesar dengan X16 yaitu 0,176 sehingga X16 dimasukkan dalam model. Selanjutnya, memodelkan X19 dengan X9, X6, X12, X7, X11 dan X16 untuk mengetahui apakah X9, X6, X12, X7, X11 dan X16 layak masuk dalam model dengan melakukan pengujian-pengujian yang diperlukan. Berdasarkan output komputer maka X16 tidak layak 
masuk dalam model karena koefisien regresi $(\beta)$ tidak signifikan pada $\alpha=0,05$ dengan pengujian secara individu walaupun pengujian secara serentak signifikan sehingga proses seleksi stepwise dihentikan dan variabel prediktor yang masuk dalam model adalah yaitu X9, X6, X12, X7 dan X11.

Berdasarkan hasil analisis regresi dengan metode stepwise didapatkan model terbaik yaitu $\mathrm{Y}=-1.15106+$ 0.36900 X6 -0.41714 X7 + 0.31896 X9 + $0.17435 \mathrm{X} 11+$ 0.77513 X12. Model tersebut menunjukkan bahwa kepuasan mempunyai hubungan yang positif dengan variabel prediktor hal ini terlihat dari nilai koefisien yang positif kecuali X7 (aktivitas e-commerce). Aktifitas $E$ commerce (X7) mempunyai nilai korelasi positif dengan kepuasan ketika dilakukan secara individu, akan tetapi dalam model terlihat negatif hal ini berarti bahwa X7 berhubungan dengan variabel prediktor yang lain. Bukti adanya hubungan yang signifikan antara X7 dengan variabel yang lain adalah nilai korelasi antara X7 dan X12 cukup signifikan yaitu sebesar 0,792.

Langkah selanjutnya dilakukan pengujian terhadap residual untuk mengatahui apakah model yang didapatkan layak untuk digunakan memprediksi dan menggambarkan data. Ada beberapa asumsi klasik dalam regresi linear yang harus dipenuhi diantaranya :

(1) Fenomena yang diukur adalah linear

Uji linearity dapat dilakukan dengan erbagai cara diantaranya dengan melihat plot antara residual dengan prediksi (fit). Kelinearan terlihat jika grafik terlihat seperti garis lurus dan tidak membuat pola seperti bentuk kuadaratik ataupun kubik. Gambar 2 menunjukkan bahwa plot menyerupai garis lurus sehingga model regresi yang didapatkan adalah linear. Disamping itu juga dilihat plot antara variabel respon dengan variabel prediktor yang diduga berpengaruh secara parsial. Berdasarkan Gambar 1 terlihat bahwa plot tersebut menyerupai garis lurus, sehingga dapat dikatakan bahwa fenomena yang diukur sudah linear.

(2) Residual homogen dalam varian

Uji homogenitas varian juga dapat dilihat dari plot antara rasidual dan prediksi. Homogenitas varian terlihat jika tidak terdapat pola bertambah atau berkurangnya residual pada plot yang didapatkan. Gambar 2 menunjukkan bahwa tidak terdapat pola tersebut maka dapat dikatakan bahwa asumsi kedua terpenuhi yaitu homogen dalam varian.

(3) Residual independen

Uji independen dilakukan dengan melihat plot antara residual dengan waktu (urutan oservasi). Hal ini dilakukan dengan pertimbangan bahwa jika terdapat trend atau pola antara residual dengan waktu maka residual tidak independen atau tergantung dengan waktu sebelumnya atau dalam beberapa literatur disebut autokorelasi. hasil plot ini dapat dilihat pada Gambar 2 yang menunjukan bahwa tidak terdapat trend pada grafik tersebut sehingga residual sudah independen.

(4) Residual berdistribusi normal

Distribusi normal dari suatu data dapat diketahui dengan melakukan uji kolmogorov smirnov dan melihat normal probability plot. Selain itu juga dapat dilihat dari histogram data tersebut. Gambar 2 menunjukkan bahwa residual sudah berdistribusi normal berdasarkan plot yang didapat yaitu mendekati garis lurus. Disamping itu juga terlihat bahwa histogram dari residual menyerupai bentuk lonceng.

Tabel 6. Perbedaan Fasilitas dari 4 Software yang digunakan

\begin{tabular}{|c|c|c|c|c|c|}
\hline No. & Fassilitas & SPSS & MINTAB & SAS & $R$ \\
\hline 1 & $\begin{array}{l}\text { Metode } \\
\text { selekgi }\end{array}$ & $\begin{array}{l}\text { enter forward, } \\
\text { remove, } \\
\text { backward dan } \\
\text { stepwise }\end{array}$ & $\begin{array}{l}\text { best subset, } \\
\text { stepwise(forward } \\
\text { dan backward) }\end{array}$ & $\begin{array}{l}\text { forward backwad, } \\
\text { stepwisemaxR, } \\
\text { minRRsouare }\end{array}$ & $\begin{array}{l}\text { stepwise } \\
\text { (forward dan } \\
\text { backward) }\end{array}$ \\
\hline 2 & $\begin{array}{l}\text { signifikan } \\
\text { level }\end{array}$ & nillad F dan a. & nilai F dan a. & nilai F dan o. & nilai $\mathrm{AIC}$ \\
\hline 3 & yijistatistila & $\begin{array}{l}\text { influence, } \\
\text { multikelinearitas } \\
\text { danplot } \\
\text { normalitas }\end{array}$ & $\begin{array}{l}\text { multiliolinearitass, } \\
\text { plotnormalitas, } \\
\text { plotesidual }\end{array}$ & $\begin{array}{l}\text { influence, } \\
\text { multikolineratas, } \\
\text { heterososkedastisitas, } \\
\text { autokorelasi, notmalitas }\end{array}$ & $\begin{array}{l}\text { influence, } \\
\text { plot } \\
\text { normalits }\end{array}$ \\
\hline
\end{tabular}

Setelah melakukan analisis dengan 4 software maka tidak ada perbedaan dalam output yang dihasilkan. Ada beberapa peredaan fasilitas yang dipunyai masing-masing software yang digunakan diantaranya dapat dilihat dalam Tabel 6 .

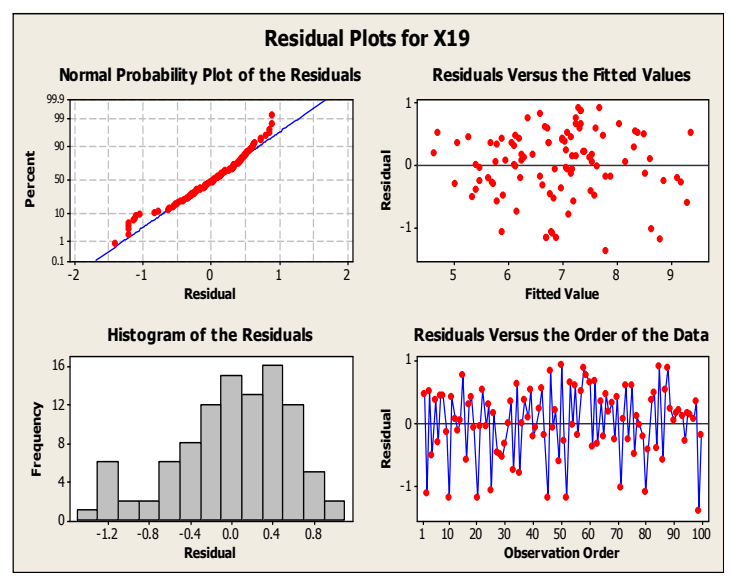

Gambar 2. Plot-plot Residual dari Variabel Respon

\section{KESIMPULAN}

Berdasarkan hasil analisis dan pembahasan maka dapat disimpulkan bahwa model terbaik dari penelitian yang dilakukan adalah $\mathrm{Y}=-1.15106+0.36900 \mathrm{X} 6-$ $0.41714 \mathrm{X} 7+0.31896 \mathrm{X} 9+0.17435 \mathrm{X} 11+0.77513 \mathrm{X} 12$ yang artinya bahwa kepuasan pelanggan secara signifikan dipengaruhi oleh tanggapan terhadap komplain, kualitas produk, image dari sales aktivitas e-commerce, dan product line. Hal ini dikuatkan dengan terpenuhinya asumsi-asumsi yang diperlukan dalam analisis regresi. Disamping itu, berdasarkan perbedaan software yang digunakan secara umum mengeluarkan hasil yang sama dengan metode yang sama. Penulis menyarankan untuk menggunakan software SAS karena dalam fasilitas yang lain lebih lengkap dibandingkan dengan software yang lain. 


\section{DAFTAR PUSTAKA}

Braun, W.J and Murdoch, D.j. (2007). A First Course in Statistical Programming with $R$. Cambridge University Press, New York.

Brown, C. E. (1993). Use of Principle Component, Correlation and Stepwise Multiple Regression Analyses to Investigate Selected Phisical and Hydraulic Properties of Carbonate-Rock Aquifers. Journal of Hydrology, 147(1-4), 169-195.

Cohen, J.,Cohen, P., West, S.G., and Aiken, L.S. (2003). Applied Multiple Regression/Correlation Analysis for The Behavioral Sciences. Third Edition. Lawrence Elbaum Associates, Mahwah : New Jersey.

Drapper and Smith. (1992). Analisis Regresi Terapan. PT Gramedia Pustaka Utama, Jakarta.

Hair, J.F., Anderson, R.E, Black, W.C., Babin, B.J., and Tatham,R.L, (2006). Multivariate Data Analysis. Sixth edition. Prentice Hall International : UK.

Ho, R. (2006). Handbook of Univariate and Multivariate Data Analysis and Interpretation with SPSS, Chapman \& Hall /CRC, Taylor and Francis Group.

Johnson, R.A. and Wichern, D.W. (2002). Applied Multivariate Statistical Analysis. Fifth edition, Prentice Hall Inc. Upper Saddle River : NJ.

Khattree, R., and Naik, D.N. (1999). Applied Multivariate Statistics with $S A S^{\circledR}$ Software. Second Edition. SAS Institute Inc.,Cary, NC : USA.

Kokaly, R.F. and Clark, R.N. (1999). Spectroscopic Determination of Leaf Biochemistri Using BandDepth Analysis of Absorption Features and Stepwise Multiple Linear Regression. Remote Sensing of Environment, 67(3), 267-287.

Nielsen, B. R., Stapelfeldt, H., and Skibsted, L.H. (1997). Early Prediction of The Shelf-Life of Medium-Heat Whole Milk Powders Using Stepwise Stepwise Multiple Regression and Principal Component Analysia. International Dairy Journal, 7(3), 341348.

Pujiati, (2005). Analisis Regresi Berganda Untuk Mengetahui Hubungan Antara Beberapa Aktifitas Promosi Dengan Penjualan Produk. Makalah Tugas Mata Kuliah Analisis Regresi. Program Pascasarjana FMIPA Jurusan Statistika Institut Teknologi Sepuluh Nopember, Surabaya.

Schlotzhauer, S.D. and Littell, R.C. (1997). SAS ${ }^{\circledR}$ System for Elementary Statistical Analysis. Second Edition. SAS Institute Inc.,Cary, NC : USA.

Supriyono, (2007). Analisis Perbandingan Logika Fuzzy Dengan Regresi Berganda Sebagai Alat Peramalan. Seminar Nasional III SDM Teknologi Nuklir, Jogyakarta.

Sun, Y.X., Zhao, G.C., and Yan,W. (1995). Age Estimation on The Female Sternum by Quantification Theory I and Stepwise Regression Analysis. Forensic Science International, 74(1-2), 57-62.

Wilkinson, L.(1979). Test of Significant in Stepwise Rregression. Psychological Bulletin, 86(1),168-174. 